\title{
Exogenous nitric oxide donor sodium nitroprusside ameliorates root architecture and growth performance in young budding polybagged plants of rubber (Hevea brasiliensis)
}

\author{
N M C Nayanakantha*, P D Pathirana*, A M W K Senevirathna* and \\ P Seneviratne* \\ * Dept. of Plant Science, Rubber Research Institute of Sri Lanka, Dartonfield, Agalawatta
}

Received: 08 April 2014

\begin{abstract}
Shoot die back condition has been observed in young budding rubber plants (Hevea brasiliensis Muell. Arg.) raised in polybags under hot and dry weather conditions in the recent past, partly due to failure of the root system, and therefore, it is imperative to find ways to improve the root system while enhancing other growth performances of rubber seedlings. In the present study, the effect of sodium nitroprusside (SNP) as a nitric oxide (NO) donor on root architecture and growth characteristics of polybagged rubber seedlings raised under glass house conditions and at two growth stages (one month and five months after transplanting) was investigated. In this communication, we report that exogenous application of SNP to rubber seedlings greatly induced lateral and feeder roots and root hair emergence and elongation, while improving primary root (tap root) growth and other growth characteristics of the shoot i.e., stem diameter, shoot height, leaf area and shoot and root biomasses in a dose-dependent manner. SNP concentration between $50 \mu \mathrm{M}-300 \mu \mathrm{M}$ was found to be the best range. To our knowledge, this is the first report on exploring the effect of $N O$ on root architecture and growth performance of rubber seedlings by exogenous application of SNP.
\end{abstract}

Key words: concentration, growth, nitric oxide, phytohormones, root architecture, rubber, Sodium nitroprusside

\section{Introduction}

The standard practice adopted in the commercial propagation of rubber (Hevea brasiliensis) clones is by grafting buds of selected clones on to unselected seedling rootstocks raised in polybags using young budding technique. In young budding, germinated seeds are placed directly in polybags and the plants that emerge are allowed to grow for up to 3-4 months until the diameter of the stem becomes 
6-7mm. The plants are then budgrafted and successfully grafted seedlings are cut-back in order to promote the growth of the scion (Seneviratne, 2001). However, scions of some plants die back about 4-6 weeks after cut-back, particularly under hot and dry weather conditions (Dharmakeerthi et al., 2008). The die back situation might be due to the failure of the root system to meet the evapo-transpiration demand of the shoot (Dharmakeerthi et al., 2008). Therefore, it is imperative to find ways to improve the root system of the stock plants to mitigate the adverse effect of shoot die back.

Root system performs the essential tasks of providing water, nutrients and physical support to plants. Rubber tree roots show a gradient for growth potential: taproots (primary root) (first order) have indefinite rapid growth and dense ramification, unlike tertiary roots (third order) which have short and slow growth with very few branches, secondary roots (second order) being split between many intermediate cases depending on their inception date and location (Le Roux and Pages, 1994). Early secondary roots (ESR), which form a whorl at the base of the tap root of rubber seedlings, are preformed during embryogenesis (Premakumari and Sobhana, 1995). The length of the primary root (PR), the density of lateral (secondary) roots (LRs) and development of root hairs determine the architecture of the root system, and this, in turn, plays a major role in determining whether a plant will succeed in a particular environment (Malamy and Benfey, 1997). The number of LRs is not predetermined in plant development and therefore, each plant integrates information from its environment into the "decisions" it makes about root formation (Malamy and Ryan, 2001). Nutrients are one of the major environmental signals that affect LR development. In soils or media with patchy nutrient distribution, LRs preferentially proliferate in the nutrient-rich zone (Zhang and Forde, 1999).

LR development is also under hormonal control. Many lines of experimental evidence strongly support a role for auxin during this process. Application of exogenous auxin results in increased initiation of LRs (Blakely et al., 1988). In general, plant hormones integrate a multitude of internal and external cues into coordinated metabolic and developmental responses, which, in turn, maximize plant fitness under diverse ontogenetic and environmental contexts. To effectively carry out such critical function, distinct plant hormones intensively interact among themselves and also with other endogenous signaling substances (Santner et al., 2009).

Among these hormone-interacting molecules, the gaseous free radical nitric oxide (NO) has recently gained special interest in the research community given its involvement in a number of signaling cascades controlling plant responses ranging from seed germination to plant 
senescence (Mur et al., 2012; Freschi, 2013; Kong et al., 2014). NO is required for root organogenesis (Pagnussat et al. 2002), the formation of adventitious roots (Pagnussat et al., 2003), lateral root development (CorreaAragunde et al., 2004) and root hair formation (Lombardo et al., 2006). Various nitric oxide donors such as Sodium nitroprusside (SNP), S-nitroso$\mathrm{N}$-acetylpenicillamine (SNAP) and Snitrosoglutathione (GSNO) have been developed (Mur et al., 2012) but SNP is frequently used (Correa- Aragunde et al., 2004; Mur et al., 2012; Chohan et al., 2012; Kong et al., 2014).

Apart from root development, evidence has been obtained for the involvement of NO in other growth and developmental processes (Tan et al., 2008). NO stimulates seed germination and de-etiolation and inhibits hypocotyl elongation (Beligni and Lamattina, 2000); alleviates drought stress in wheat seedlings (Tian and Lei, 2006) and improved the rate of photosynthesis, chlorophyll content, transpiration rate and stomatal conductance in cucumber seedlings (Fan et al., 2007). Nitric oxide has also been implicated in defense against Pseudomonas syringae in tobacco and Botrytis cinerea in Arabidopsis (Arabidopsis thaliana) (Mur et al., 2012). Although great strides have been made in recent years in understanding the mechanistic relationship between NO and phytohormones in certain physiological responses, the exact nature of the interaction between these substances in many developmental, metabolic, and defense events in different plant species remains remarkably elusive. In view of this, present study aimed at exploring the effect of exogenous SNP (as a NO donor) on root architecture and growth characteristics of rubber seedlings. We report here that, exogenous SNP, in a dose-dependant manner, ameliorates the root architecture and growth characteristics of rubber seedlings. To our knowledge, this is the first report on application of SNP to rubber seedlings to study the effect of NO.

\section{Materials and Methods Growing of rubber seedlings}

The study was conducted in a glass house at the Dartonfield estate of the Rubber Research Institute of Sri Lanka (RRISL). Seeds were collected from clone RRIC 100 at early seed fall from Warakapola, sown in a germination bed filled with sand. After 14 days, uniformly germinated seedlings (Fig. 2) were selected and transplanted at the rate of one in a black polythene bag, gauge 300 and having lay-flat dimensions of $15 \mathrm{~cm}$ diameter and $37 \mathrm{~cm}$ height, filled with soil. Soils from the Agalawatta series were collected from the surface layer $(0-15 \mathrm{~cm}$ depth $)$. Soils were sieved through a $1 \mathrm{~cm}$ mesh to remove large lateritic gravel before filling the bags. Nitric Oxide (NO) donor Sodium nitroprusside (SNP) was from Sigma, (MO, USA). After transplanting, each seedling was supplied with water (@50ml twice a day). 


\section{Treatments with SNP}

Batches of 40 plants were supplied separately with water (@50ml twice a day) containing SNP at various concentrations, viz., $5 \mu \mathrm{M}, 10 \mu \mathrm{M}, 50$ $\mu \mathrm{M}, 100 \mu \mathrm{M}, 200 \mu \mathrm{M}, 300 \mu \mathrm{M}, 500$ $\mu \mathrm{M}$ and $1000 \mu \mathrm{M}$ for five consecutive days. Control seedlings were provided with same amount of water devoid of SNP. From sixth day onwards, each plant was provided with $100 \mathrm{ml}$ of water per day, as described earlier, until two months. For the next three months, plants were watered normally with an overhead irrigation method.

Each treatment had 40 single plant replicates and they were arranged in a randomized complete block design in a glass house. Two weeks after transplanting, application of chemical fertilizers, i.e. young budding fertilizer mixture in liquid form, into seedlings was started and continued at two-week intervals. All other management practices were same as recommended by the Rubber Research Institute of Sri Lanka (Anon, 2009).

\section{Measurement of growth parameters}

Growth characteristics and the root architecture of the plants were assessed at three stages, after 2 weeks, one month and five months from transplanting. At each growth stage, 5 plants from each treatment were selected randomly. The root system from each plant was washed gently under running water over a 0.5 $\mathrm{mm}$ sieve and the adhering soil and dust particles were carefully removed. Morphological attributes viz., diameter of stem $(1 \mathrm{~cm}$ above the base of the seedling), number of early secondary roots (ESR), number of lateral roots (LRs) (either single or in bunches of feeder roots), length of primary root (PR), length of ESRs and Length of LRs were taken after one month from transplanting. Other attributes such as fresh weights of PR, LRs + ESRs, stem, leaves, together with stem diameter, plant height and number of leaves were taken after five months from transplanting. Leaf area was determined by leaf area meter (Model L1-3100, LICOR, USA).

\section{Microscopic studies for root hair analysis}

LRs and feeder roots of rubber seedlings, both at one month and five months of age and were imposed with different SNP treatments were carefully removed and fixed in FAA solution (ethanol-water-formalin-acetic acid, 10 $: 7: 2: 1, \mathrm{v}: \mathrm{v}: \mathrm{v}: \mathrm{v})$ for $48 \mathrm{~h}$. Before observing LRs and feeder roots for the occurrence of root hairs, a batch of 5 roots from each treatment was stained with trypan blue $(0.1 \%)$ and, examined in a bright-field Microscope (Model Daffodil MCX 100, MICROS, Australia) with an in-built camera. Number of root hairs was estimated by counting root hairs in the second $\mathrm{mm}$ behind the apex using the Microvisible image analyzing software (version 1.11.10). Length of the root hairs was also estimated using the same software. 


\section{Statistical analysis of data}

Significance of the observed treatment differences was tested by analysis of variance using proc GLM procedure of the SAS software package (version 9.1) and significant means were separated using the least significant difference (LSD).

\section{Results}

\section{Growth parameters}

Application of SNP greatly improved the stem diameter and root characteristics, i.e. no. of SR, length of SRs and ESRs of rubber seedlings in dose dependant manner as compared to control after one month from transplanting into polybags (Figs.1 and
The magnitude of increase in stem diameter, plant height, leaf area, fresh weights of leaf, shoot, tap root, lateral roots and shoot/root ratio was more pronounced after five months from transplanting. All the concentrations of SNP $(5 \mu \mathrm{M}-1000 \mu \mathrm{M})$ resulted in increase in almost all the morphological characteristics of rubber seedlings over the control though lower concentrations $(50 \mu \mathrm{M}-200 \mu \mathrm{M})$ were more effective. Interestingly, neither any symptoms of phytotoxicity nor abnormalities in any of the morphological attributes of the rubber seedlings were observed upon SNP treatments at any growth stage irrespective of SNP concentrations. $3)$.

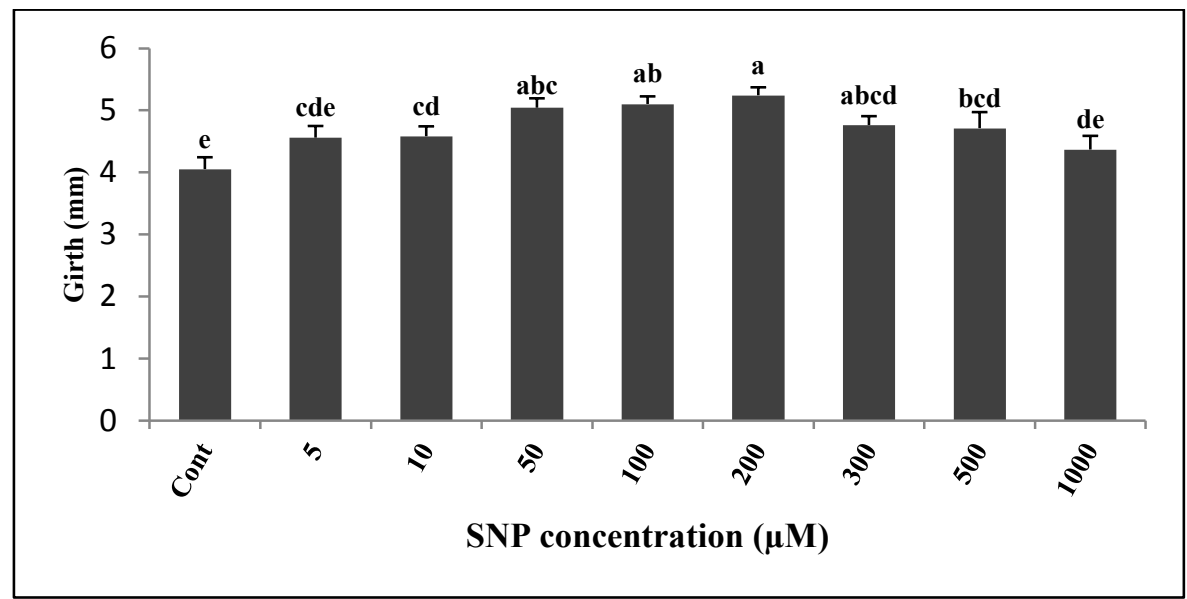

Fig. 1. Effect of $\mathrm{NO}$ on stem diameter. Rubber seedlings were treated with different concentrations of the NO donor SNP. The stem diameter at $1 \mathrm{~cm}$ above the soil level was measured and analyzed. The values are means and SE of 5 seedlings $(n=5)$. Letters indicate significant difference at $\mathrm{p} \leq 0.05$ according to LSD. Cont: Control 
In both one month and five months old seedlings, maximum stem diameter was recorded at $200 \mu \mathrm{M}$ SNP followed by $100 \mu \mathrm{M}$ and $50 \mu \mathrm{M}$ (Fig. 1 and Table 1). Although there was no significant difference $(p \leq 0.05)$ in plant height among treatments and control after one month from transplanting (results not shown), dramatic increase in plant height was observed when the plants were five months old. At this age, significantly tallest plants $(p \leq 0.05)$ were produced with SNP concentration at $50 \mu \mathrm{M}$ followed by $100 \mu \mathrm{M}, 200 \mu \mathrm{M}$, $300 \mu \mathrm{M}$ and $1000 \mu \mathrm{M}$, respectively, as compared to control (Table 1).

Interestingly, no significant effect on number of leaves due to SNP application was observed at any growth stage, i.e. at one month (results not shown) or at five months of the rubber seedlings (Table 1). Nevertheless, a significant increase $(\mathrm{p} \leq 0.05)$ in leaf area was observed in all the concentrations of SNP tested except $1000 \mu \mathrm{M}$ as compared to control (Table 1). SNP at $200 \mu \mathrm{M}$ was the best for leaf area increment followed by $50 \mu \mathrm{M}$ and 100 $\mu \mathrm{M}$, respectively (Table 1 ).

Significantly $(p \leq 0.05)$ higher fresh weight of the stem was recorded in SNP concentration at $50 \mu \mathrm{M}$ followed by 100 $\mu \mathrm{M}, 500 \mu \mathrm{M}$ and $200 \mu \mathrm{M}$ respectively after five months from transplanting (Table 2). Leaf fresh weights were also significantly $(\mathrm{p} \leq 0.05)$ higher at all the concentrations of SNP except $1000 \mu \mathrm{M}$ as compared to control in five months old seedlings (Table 2). SNP concentrations at $50 \mu \mathrm{M}$ and $100 \mu \mathrm{M}$ produced seedlings with the highest shoot fresh weights (Table 2). Nevertheless, all SNP concentrations, except $1000 \mu \mathrm{M}$, produced plants with fresh shoot weights significantly greater than that recorded for control (Table 2).

Table 1. Mean growth parameters of seedlings for shoot characteristics after five months

\begin{tabular}{|c|c|c|c|c|}
\hline Treatment & $\begin{array}{l}\text { Stem diameter } \\
\text { (mm/plant) }\end{array}$ & $\begin{array}{l}\text { Stem height } \\
\text { (cm/plant) }\end{array}$ & $\begin{array}{l}\text { No. of } \\
\text { leaves/plant }\end{array}$ & $\begin{array}{l}\text { Leaf area } \\
\left(\mathrm{cm}^{2} / \text { plant }\right)\end{array}$ \\
\hline Control & $7.39 \pm 0.35^{\mathrm{d}}$ & $81.40 \pm 3.4^{\mathrm{d}}$ & $14.2 \pm 1.68^{\mathrm{a}}$ & $1673.07 \pm 50.39^{d}$ \\
\hline 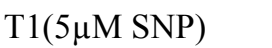 & $7.96 \pm 0.29^{\mathrm{d}}$ & $92.40 \pm 2.36^{\mathrm{c}}$ & $16.6 \pm 2.06^{\mathrm{a}}$ & $1884.04 \pm 194.55^{\mathrm{cd}}$ \\
\hline T2(10 $\mu \mathrm{M}$ SNP) & $9.04 \pm 0.21^{\mathrm{c}}$ & $94.70 \pm 3.57^{\mathrm{c}}$ & $16.8 \pm 1.07^{\mathrm{a}}$ & $2482.76 \pm 258.92^{\mathrm{abc}}$ \\
\hline T3(50 $\mu \mathrm{M}$ SNP) & $10.24 \pm 0.55^{\mathrm{b}}$ & $119.40 \pm 2.77^{\mathrm{a}}$ & $17.4 \pm 1.72^{\mathrm{a}}$ & $2602.66 \pm 330.58^{\mathrm{ab}}$ \\
\hline 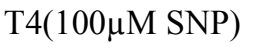 & $10.54 \pm 0.31^{\mathrm{ab}}$ & $109.00 \pm 1.30^{\mathrm{b}}$ & $16.6 \pm 0.51^{\mathrm{a}}$ & $2675.07 \pm 277.88^{\mathrm{ab}}$ \\
\hline 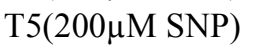 & $11.10 \pm 0.37^{\mathrm{a}}$ & $105.80 \pm 2.50^{\mathrm{b}}$ & $16.4 \pm 1.03^{\mathrm{a}}$ & $2920.75 \pm 189.76^{\mathrm{a}}$ \\
\hline 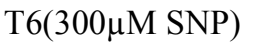 & $8.83 \pm 0.17^{\mathrm{c}}$ & $102.80 \pm 2.44^{\mathrm{b}}$ & $15.0 \pm 1.96^{\mathrm{a}}$ & $2173.35 \pm 214.84^{\text {bcd }}$ \\
\hline 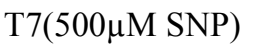 & $9.17 \pm 0.37^{\mathrm{c}}$ & $83.40 \pm 1.50^{\mathrm{d}}$ & $15.4 \pm 1.54^{\mathrm{a}}$ & $2251.42 \pm 101.40^{\mathrm{bcd}}$ \\
\hline 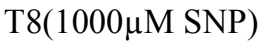 & $8.00 \pm 0.36^{\mathrm{d}}$ & $106.4 \pm 3.04^{b}$ & $14.6 \pm 1.12^{\mathrm{a}}$ & $1694.04 \pm 89.97^{\mathrm{d}}$ \\
\hline $\operatorname{LSD}(\mathrm{p} \leq 0.05)$ & 0.77 & 7.51 & 4.03 & 596.76 \\
\hline
\end{tabular}

Values followed by the same letter in a column are not significantly different at $\mathrm{p} \leq 0.05$. 
Table 2. Mean fresh weights of shoots of rubber seedlings after five months

\begin{tabular}{|c|c|c|c|}
\hline Treatment & $\begin{array}{l}\text { FW of stem } \\
\text { (g/plant) }\end{array}$ & $\begin{array}{l}\text { FW of leaf } \\
\text { (g/plant) }\end{array}$ & $\begin{array}{l}\text { FW of shoot } \\
\text { (g/plant) }\end{array}$ \\
\hline Control & $19.6 \pm 0.68^{\mathrm{g}}$ & $21.6 \pm 0.93^{b}$ & $41.2 \pm 1.31^{\mathrm{d}}$ \\
\hline $\mathrm{T} 1(5 \mu \mathrm{M}$ SNP $)$ & $28.4 \pm 1.94^{\mathrm{ef}}$ & $33.4 \pm 3.93^{\mathrm{a}}$ & $61.8 \pm 4.48^{c}$ \\
\hline $\mathrm{T} 2(10 \mu \mathrm{M}$ SNP) & $31.4 \pm 2.07^{\mathrm{de}}$ & $36.6 \pm 2.40^{\mathrm{a}}$ & $68.0 \pm 2.46^{\mathrm{bc}}$ \\
\hline $\mathrm{T} 3(50 \mu \mathrm{M}$ SNP) & $46.8 \pm 2.22^{\mathrm{a}}$ & $40.2 \pm 2.60^{\mathrm{a}}$ & $83.0 \pm 4.73^{\mathrm{a}}$ \\
\hline T4(100uM SNP) & $42.0 \pm 2.50^{\mathrm{ab}}$ & $39.4 \pm 1.08^{\mathrm{a}}$ & $81.4 \pm 2.65^{\mathrm{a}}$ \\
\hline $\mathrm{T} 5(200 \mu \mathrm{M}$ SNP $)$ & $39.4 \pm 2.21^{b c}$ & $38.6 \pm 3.87^{\mathrm{a}}$ & $75.0 \pm 5.39^{\mathrm{ab}}$ \\
\hline T6(300 $4 \mathrm{M}$ SNP) & $34.8 \pm 2.11^{\mathrm{dc}}$ & $33.2 \pm 1.98^{\mathrm{a}}$ & $68.0 \pm 3.22^{b c}$ \\
\hline $\mathrm{T} 7(500 \mu \mathrm{M}$ SNP) & $40.0 \pm 1.95^{\mathrm{bc}}$ & $39.0 \pm 3.92^{\mathrm{a}}$ & $79.0 \pm 4.84^{\mathrm{ab}}$ \\
\hline T8(1000uM SNP) & $24.0 \pm 1.16^{\mathrm{g}}$ & $22.8 \pm 1.62^{\mathrm{b}}$ & $46.8 \pm 2.47^{\mathrm{d}}$ \\
\hline $\operatorname{LSD}(p \leq 0.05)$ & 5.70 & 7.91 & 11.05 \\
\hline
\end{tabular}

Values followed by the same letter in a column are not significantly different at $\mathrm{p} \leq 0.05$.

\section{Root characteristics}

The NO donor SNP increased LR number, length of ESR, SR and number and length of root hairs in dosedependent manner in rubber seedlings. Figure 2 shows the development of LRs in 14 days old rubber seedlings treated with SNP at various concentrations. LR development was not observed in control seedlings at 14 days provided that there was no physical barrier or damage to tap root to continue its growth. The promotion of LR development was maximal at $50 \mu \mathrm{M}$ SNP at 14 days.

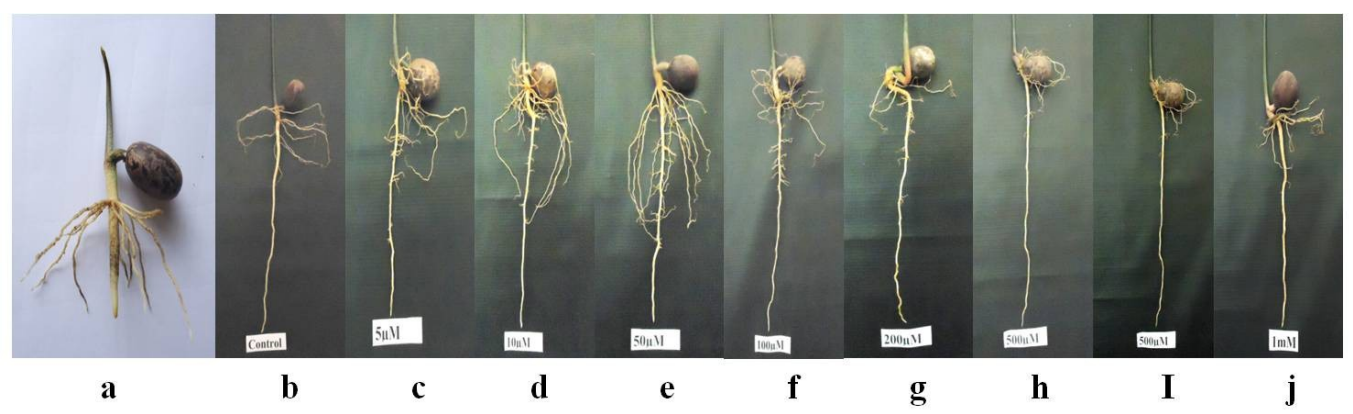

Fig. 2. Effect of NO on early secondary root (ESR), secondary root (SR) and primary root (PR) growth and development. Rubber seedlings were treated with different concentrations of the NO donor SNP and the observations were made after 14 days. a: germinated rubber seedling at the time of transplanting. b: control, c: $5 \mu \mathrm{M} \mathrm{SNP}, \mathrm{d}: 10$ $\mu \mathrm{M}$ SNP, e: $50 \mu \mathrm{M}$ SNP, f: $100 \mu \mathrm{M}$ SNP, g: $200 \mu \mathrm{M}$ SNP, h:300 $\mu \mathrm{M}$ SNP, i: $500 \mu \mathrm{M}$ SNP, j: $1000 \mu \mathrm{M}$ SNP 
The magnitude of the rooting variation was more pronounced when the seedlings reached at one month and the variations continued to exist even at five months (Table 3 and Fig. 4). SNP concentrations ranging from $50 \mu \mathrm{M}$ $300 \mu \mathrm{M}$ were the best for increase in number and length of lateral roots of one month old seedlings (Fig. 3).

Interestingly, SNP treatment did not increase the number of ESR although the length of ESR was significantly affected upon SNP treatment in dose dependant manner, $5 \mu \mathrm{M}-100 \mu \mathrm{M}$ being the best range (Fig. 3). However, the number and the length of secondary roots including the tertiary, quaternary, etc. roots (feeder roots) increased significantly $(p \leq 0.05)$ due to SNP treatment at all the concentrations as compared to control (Fig. 3).

Table 3. Mean growth parameters of seedlings for root characteristics after five months

\begin{tabular}{|c|c|c|c|c|c|}
\hline Treatment & $\begin{array}{l}\text { FW of tap } \\
\text { root inside } \\
\text { polybag } \\
\text { (g/plant) }\end{array}$ & $\begin{array}{l}\text { FW of } \\
\text { lateral roots } \\
\text { inside } \\
\text { polybag } \\
\text { (g/plant) } \\
\end{array}$ & $\begin{array}{l}\text { FW of all } \\
\text { roots } \\
\text { outside } \\
\text { polybag } \\
\text { (g/plant) } \\
\end{array}$ & $\begin{array}{l}\text { FW of total } \\
\text { roots } \\
\text { (g/plant) }\end{array}$ & $\begin{array}{l}\text { Shoot/Root } \\
\text { ratio }\end{array}$ \\
\hline Control & $7.60 \pm 0.81^{\mathrm{c}}$ & $11.60 \pm 2.11^{\mathrm{c}}$ & $3.00 \pm 0.71^{\mathrm{bc}}$ & $22.20 \pm 1.88^{\mathrm{d}}$ & $1.90 \pm 0.15^{\mathrm{bc}}$ \\
\hline $\mathrm{T} 1(5 \mu \mathrm{M}$ SNP $)$ & $8.00 \pm 0.71^{\mathrm{c}}$ & $13.60 \pm 2.62^{b c}$ & $7.20 \pm 1.39^{\mathrm{bc}}$ & $28.80 \pm 1.59^{\mathrm{cd}}$ & $2.16 \pm 0.17^{\mathrm{abc}}$ \\
\hline $\mathrm{T} 2(10 \mu \mathrm{M}$ SNP) & $8.60 \pm 0.40^{b c}$ & $14.00 \pm 3.50^{\mathrm{bc}}$ & $3.80 \pm 0.58^{\mathrm{bc}}$ & $26.40 \pm 3.76^{\mathrm{cd}}$ & $2.75 \pm 0.34^{\mathrm{a}}$ \\
\hline $\mathrm{T} 3(50 \mu \mathrm{M}$ SNP) & $13.80 \pm 0.16^{\mathrm{a}}$ & $17.40 \pm 2.32^{\mathrm{abc}}$ & $19.60 \pm 4.61^{\mathrm{a}}$ & $50.80 \pm 5.24^{\mathrm{a}}$ & $1.70 \pm 0.17^{\mathrm{c}}$ \\
\hline $\mathrm{T} 4(100 \mu \mathrm{M}$ SNP) & $13.20 \pm 1.93^{\mathrm{a}}$ & $19.60 \pm 1.78^{\mathrm{ab}}$ & $7.00 \pm 1.70^{\mathrm{bc}}$ & $39.80 \pm 3.33^{\mathrm{b}}$ & $2.09 \pm 0.16^{b c}$ \\
\hline T5(200 $\mu \mathrm{M}$ SNP $)$ & $12.00 \pm 0.89^{\mathrm{a}}$ & $22.20 \pm 3.18^{\mathrm{a}}$ & $4.52 \pm 1.42^{\mathrm{bc}}$ & $38.72 \pm 2.57^{\mathrm{b}}$ & $2.00 \pm 0.25^{\mathrm{bc}}$ \\
\hline T6(300 $\mu \mathrm{M}$ SNP $)$ & $12.20 \pm 1.69^{\mathrm{a}}$ & $19.80 \pm 3.12^{\mathrm{ab}}$ & $8.80 \pm 4.32^{\mathrm{b}}$ & $40.80 \pm 4.61^{\mathrm{b}}$ & $1.77 \pm 0.25^{\mathrm{bc}}$ \\
\hline $\mathrm{T} 7(500 \mu \mathrm{M}$ SNP $)$ & $11.40 \pm 0.75^{\mathrm{ab}}$ & $20.00 \pm 1.22^{\mathrm{ab}}$ & $2.62 \pm 1.07^{\mathrm{bc}}$ & $34.02 \pm 0.85^{\mathrm{bc}}$ & $2.32 \pm 0.13^{\mathrm{ab}}$ \\
\hline $\mathrm{T} 8(1000 \mu \mathrm{M}$ SNP $)$ & $8.20 \pm 0.73^{\mathrm{c}}$ & $15.20 \pm 1.98^{\mathrm{bc}}$ & $1.40 \pm 0.24^{\mathrm{c}}$ & $24.80 \pm 1.16^{\mathrm{cd}}$ & $1.90 \pm 0.14^{\mathrm{bc}}$ \\
\hline LSD $(p \leq 0.05)$ & 2.88 & 6.49 & 6.45 & 9.22 & 0.58 \\
\hline
\end{tabular}

Values followed by the same letter in a column are not significantly different at $\mathrm{p} \leq 0.05$. 


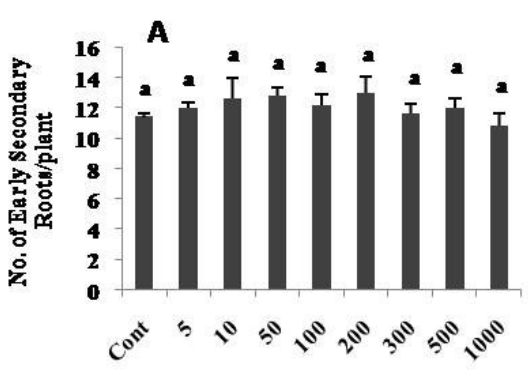

SNP concentration ( $(\mu M)$

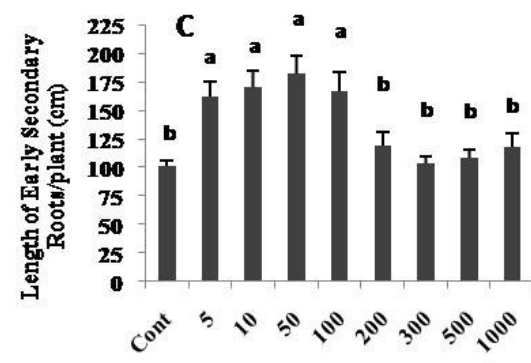

SNP concentration ( $\mathrm{\mu M}$ )

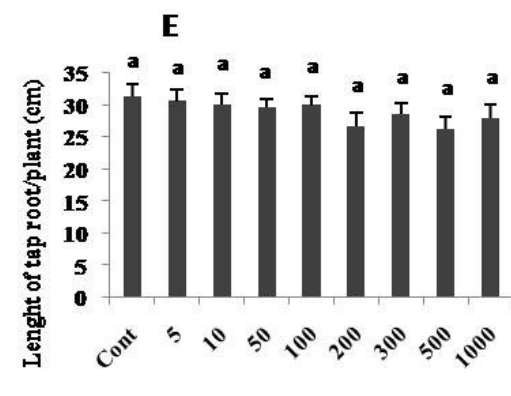

SNP concentration ( $\mu M$ )
B

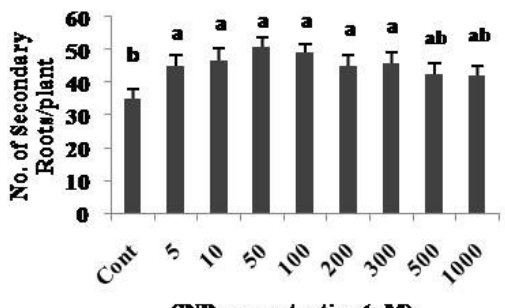

SNP concentration (pM)

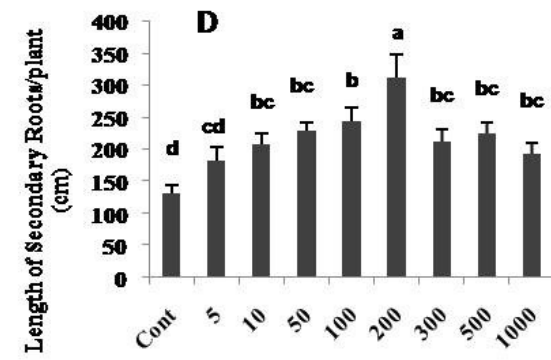

SNP concentration

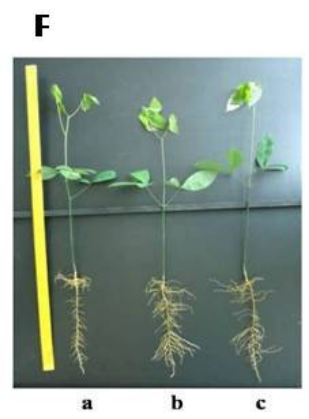

Fig. 3. Effect of NO on early secondary root (ESR) number, secondary root (SR) number, primary root (PR) length, ESR length and SR length. Rubber seedlings were treated with different concentrations of the NO donor SNP. The number of ESRs and LRs per seedling $(a, b)$ and the length of the ESRs, LRs and PR (c, d, e) were analyzed. The values are means and $\mathrm{SE}$ of 5 seedlings $(\mathrm{n}=5)$. Letters indicate significant difference at $\mathrm{p} \leq 0.05$ according to LSD. Cont: Control. The photograph shows the rooting difference in one-month-old seedlings due to SNP treatment at two concentrations. a : control, b: $50 \mu \mathrm{M} \mathrm{SNP}$, c: $100 \mu \mathrm{M}$ SNP. A wooden meter ruler was used as a scale. 


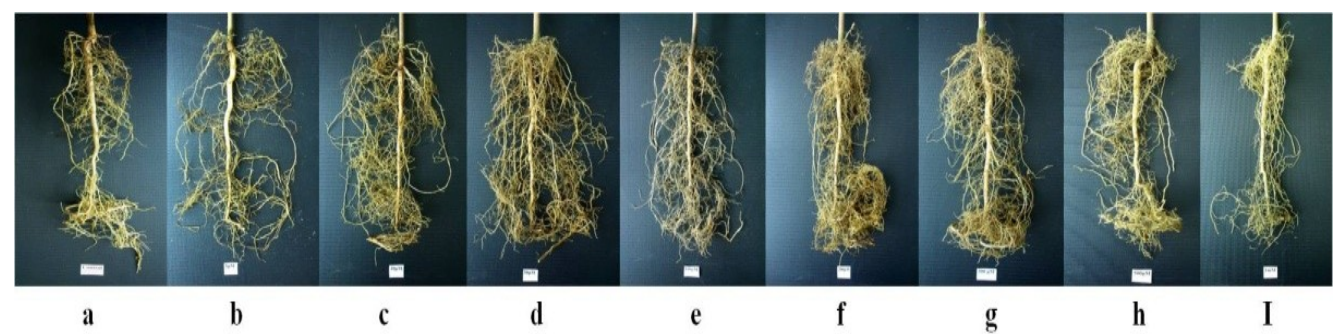

Fig. 4. Effect of NO on the development of entire root system inside the polybags. Rubber seedlings were treated with different concentrations of the NO donor SNP. The representative photographs were taken after five months. a: control, b: $5 \mu \mathrm{M} \mathrm{SNP}$; : $10 \mu \mathrm{M}$ SNP, d: $50 \mu \mathrm{M}$ SNP, e: $100 \mu \mathrm{M}$ SNP, f: $200 \mu \mathrm{M}$ SNP, g:300 $\mu \mathrm{M}$ SNP, h: 500 $\mu \mathrm{M}$ SNP, i: $1000 \mu \mathrm{M}$ SNP

\section{Microscopic analysis of root hairs}

The number and the length of root hairs of the feeder roots were greatly increased by treatment with SNP at all the concentrations, although low concentrations $(5 \mu \mathrm{M}-50 \mu \mathrm{M})$ were more effective (Figs. 5 and 6 ). Low SNP concentrations resulted in entire root surface, up to $3-5 \mathrm{~mm}$ from the root cap, being covered by root hairs. Generally in control seedlings root hairs were found scattered or in groups along the length of the feeder roots. Moreover, root hairs were not observed on secondary roots that arose from the tap root of the control seedlings at one month of age. However, in some of the secondary roots of plants treated with SNP $(5 \mu \mathrm{M}-50 \mu \mathrm{M})$ development of root hairs was evident at one month age. In overall, SNP concentration at $50 \mu \mathrm{M}$ $300 \mu \mathrm{M}$ improved both shoot and root characteristics of rubber seedlings compared to other treatments.

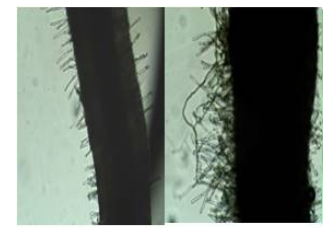

a

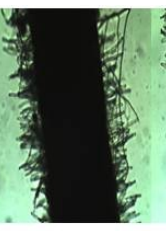

C

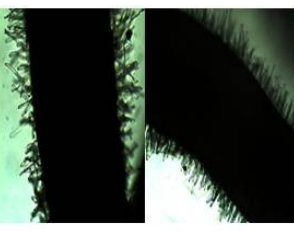

d

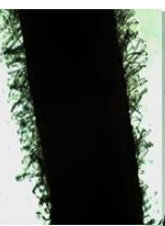

f

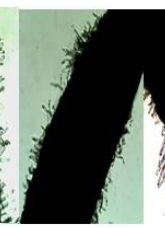

g

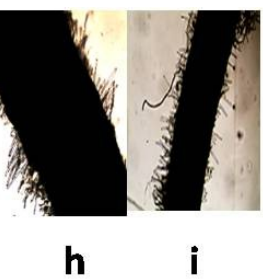

Fig. 5. Effect of NO on root hair number and length. Rubber seedlings were treated with different concentrations of the NO donor SNP. The representative photographs of feeder roots with root hairs were taken after five months. a: control, b: $5 \mu \mathrm{M}$ SNP; $\mathrm{c}$ : $10 \mu \mathrm{M}$ SNP, d: $50 \mu \mathrm{M}$ SNP, e: $100 \mu \mathrm{M}$ SNP, f: $200 \mu \mathrm{M}$ SNP, g:300 $\mu \mathrm{M}$ SNP, h: 500 $\mu \mathrm{M}$ SNP, i: $1000 \mu \mathrm{M}$ SNP 

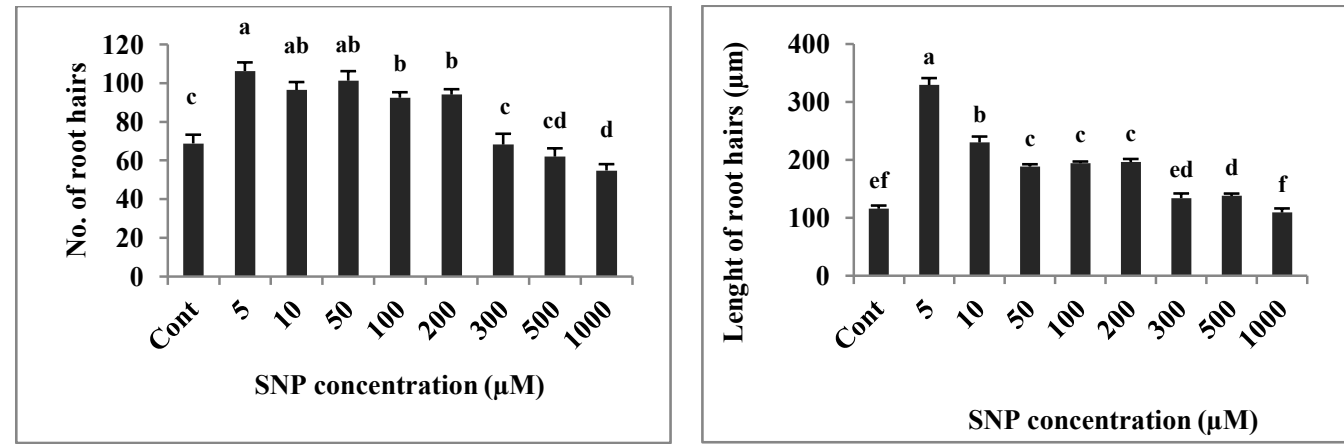

Fig. 6. Effect of NO on root hair number and length. Rubber seedlings were treated with different concentrations of the NO donor SNP. The number and the length of root hairs were estimated on feeder roots of five months old rubber seedling after staining with trypan blue. The values are means and SE of 5 roots $(n=5)$. Cont: Control. Letters indicate significant difference at $\mathrm{p} \leq 0.05$ according to LSD.

\section{Discussion}

Roots are the organs that ensure nutrient and water supply for the plant. For this purpose root architecture has to be adapted to alleviate the changing environmental conditions. The plasticity to modulate the root architecture is one way to overcome the inability of plants to move towards water or nutrients stores. In this report, we present that exogenous SNP as a NO donor ameliorates three processes that define the root architecture of rubber seedlings: primary root growth, lateral root development and growth of root hairs. In rubber seedlings, $\mathrm{NO}$ can modify the root architecture by increasing the number of secondary roots, branching of secondary roots and thereby increasing the number of feeder roots, lengths of secondary and feeder roots, number and length of root hairs in dose dependant manner and, thus, enabling the seedlings for both horizontal and vertical exploration of nutrients within the polybag.

Typically, most of the roots found in polybags show a rapid decline in both elongation rate and diameter and stop growing when the time of flushing, although some of them continue to grow thereafter (Le Roux and Pages, 1994; Thaler and Pages, 1996). This decrease in root number has been interpreted in terms of enhanced competition for carbohydrates induced by the growth of the shoot (Thaler and Pages, 1996). Moreover, a rapid degradation of lateral and feeder roots has been observed 4-6 weeks after cut back from budgrafting, leading to a situation called "scion die back" in some plants under hot and dry weather conditions (Dharmakeerthi et al., 2008). Therefore, it could be hypothesized that the increase in number and length of lateral and feeder 
roots and the density of root hairs due to SNP treatment could alleviate the adverse effect exerted during the critical stage of post bud grafting period.

Nitric oxide (NO) is currently considered ubiquitous signal in plant systems, playing significant roles in a wide range of responses to environmental and endogenous cues, most of them reported in roots (Pagnussat et al., 2002; CorreaAragunde et al., 2004; Lombardo et al., 2006). Studies conducted during the induction of diverse plant responses have demonstrated that NO may also affect biosynthesis, catabolism/ conjugation, transport, perception, and/or transduction of almost all the phytohormones, i.e. auxins, gibberellins, cytokinins, abscisic acid, ethylene, salicylic acid, jasmonates, and brassinosteroids (Freschi, 2013). During the signaling events leading to these plant responses, NO frequently interacts with plant hormones and other endogenous molecules, at times originating remarkably complex signaling cascades (Freschi, 2013). Instead of a unique or very few receptors, NO likely interacts with a wide range of target proteins via direct modification of protein structure (Freschi, 2013). Through these chemical modifications of target proteins, NO may trigger changes in their activities and cellular functions, ultimately leading to the transduction of the NO message into plant responses.

Synergistic effects of auxin and NO have been observed during the regulation of a series of plant responses, including the interplay between these molecules during adventitious roots formation (Pagnussat et al., 2004), lateral root development (CorreaAragunde et al., 2004) and root hair initiation and elongation (Lombardo et al., 2006). In virtually all of these cases, NO was identified to function downstream of auxins, apparently through linear signaling pathways. A reduction in primary root length and an increase in lateral root formation were observed in tomato seedlings treated with $200 \mu \mathrm{m}$ of the NO donor SNP (Correa-Aragunde et al., 2004). However, in contrary to the results of Correa Aragunde (2004), in the present study, there was no reduction in length of the primary root at any SNP concentrations tested $(5 \mu \mathrm{M}$ to 1000 $\mu \mathrm{M})$ as compared to control, at any growth stage of the rubber seedlings. Instead, SNP treatment increased the fresh weight of primary root in dose dependant manner. This is highly favourable for a woody perennial tree like rubber for better anchorage after field establishment.

In the present study, SNP treatment increased not only the morphological parameters, but also some other physiological parameters, i.e., chlorophyll content and net photosynthesis rate (results not shown) as compared to control irrespective of concentrations of SNP. NO has also shown to have improved the leaf size and chlorophyll content in peanut plants (Arachis hypogaea L.) (Kong et al., 
N M C Nayanakantha et al.

2014). Here, SNP promoted Fe uptake, translocation and activation; modulated the balance of mineral elements; and protected $\mathrm{Fe}$ deficiency induced oxidative stress in peanut plants (Kong et al., 2014). Zhang et al. (2012) showed that SNP application improved net photosynthesis and thereby increased the yield. Further, SNP treatment enhanced the accumulation of total dry matter content and partitioning towards different plant parts in chick pea (Cicer arietinum) (Chohan et al., 2012).

NO is also known to be involved in vegetative growth processes of the shoot (Zhang et al., 2003; An et al., 2005), cell division (Otvos et al., 2005) and xylem differentiation (Gabaldon et al., 2005). Direct impact of NO on the cytokinin signaling pathway has recently been uncovered (Feng et al., 2013). A number of studies have reported rapid and dose-dependent increases in NO production triggered by micromolar concentrations of cytokinins in intact seedlings (Shen et al., 2012). Concentrations between 50-200 $\mu \mathrm{M}$ SNP had previously been demonstrated to be functional in a number of biological systems (Beligni and Lamattina 2000; Garcia-Mata and Lamattina, 2001). $150 \mu \mathrm{M}$ SNP releases $0.5 \mu \mathrm{M} \mathrm{NO}$, in solution, during the first $48 \mathrm{~h}$ (Garcia-Mata and Lamattina, 2001). Therefore, the improved growth characteristics of rubber seedlings could be due to the beneficial effects of SNP in modifying phytohormone signaling pathways through NO leading to favourable allocation of photoassimilates.

During the present study, rubber seedlings were grown in a glass house with a high mid day temperature (38$45^{\circ} \mathrm{C}$ ) prevailed during SeptemberJanuary (2013-2014). Therefore, one can argue that the plants had been subjected to heat stress to a certain extent. This might be the reason for somewhat reduced stem diameter of glass house grown control seedlings as compared to the seedlings grown under nursery condition after five months (results not shown). Nevertheless, SNP treated plants performed well as compared to control even under such heat stress conditions prevailed in the glass house. Previous studies have demonstrated that the exogenous NO mitigated decrease in plant growth caused by drought and heat through increasing antioxidant enzymes (superoxide dismutase, catalase and ascorbate peroxidase) and thereby alleviating oxidative damage, accelerating proline accumulation, enhancing photosynthesis (Farooq et al., 2008; Tan et al., 2008; Anjum et al., 2011) and interacting with abscisic acid to induce stomatal closure (Garcia-Mata and Lamattina, 2002). Therefore, the improved growth characteristics of rubber seedlings in all the aspects under glass house conditions could be directly attributed to the beneficial effect of SNP as a NO donor in modifying phytohormone signalling pathways, enhancing antioxidant enzyme activity and thereby increase in nutrient uptake 
and effective allocation of photoassimilates. To our knowledge, this is the first report in exploring the effect of NO on root architecture and growth performance of rubber seedlings by exogenous application of SNP.

\section{Acknowledgements}

Technical support extended by Ms. Hasangi Madushani and Mrs Suneetha Wijesekera during data collection and statistical analysis done by Dr. (Mrs.) Wasana Wijesuriya are gratefully acknowledged.

\section{References}

An, L, Liu, Y, Zhang, M, Chen, $\mathrm{T}$ and Wang, X (2005). Effects of nitric oxide on growth of maize seedling leaves in the presence or absence of ultraviolet-B radiation. Journal of Plant Physiology 162, 317-326.

Anjum, S A, Xie, X, Wang, L, Saleem, M F, Man, C and Lei, W (2011). Morphological, physiological and biochemical responses of plants to drought stress. African Journal of Agricultural Research 6, 2026-2032.

Anon (2009). Production of budded plants. Advisory Circular. Rubber Research Institute of Sri Lanka.

Beligni, M V and Lamattina, L (2000). Nitric oxide stimulates seed germination and de-etiolation, and inhibits hypocotyl elongation, three light-inducible responses in plants. Planta 210 (2), 215221.

Blakely, L M, Blakely, R M, Colowit, P M and Elliot, D S (1988). Experimental studies on lateral root formation in radish seedlings roots. Analysis of the dose-response to exogenous auxin. Plant Physiology 87, 414-419.
Casimiro, I, Marchant, A, Bhalerao, R, Beeckman, T, Dhooge, S, Swarup, R, Graham, N S, Inze, D, Sandberg, G, Casero, P J and Bennett, M J (2001). Auxin transport promotes Arabidopsis lateral root initiation. Plant Cell 13, 843-852.

Chohan, A, Parmar, U and Raina, S K (2012). Effect of Sodium Nitroprusside on morphological characters under chilling stress in chickpea (Cicer arietinum L.). Journal of Environmental Biology 33, 695-698.

Correa-Aragunde, N, Graziano, $\mathrm{M}$ and Lamattina, L (2004). Nitric oxide plays a central role in determining lateral root development in tomato. Planta 218, 900-905. doi: 10.1007/s00425-0031172-7.

Dharmakeerthi, R S, Senevirathna, A M W $\mathrm{K}$, Edirimanne, $\mathrm{V} \mathrm{U}$ and Chandrasiri, J A S (2008). Effect of stock pruning on shoot and root growth of budded polybag plants of Hevea brassiliensis. Natural Rubber Research 21 (1 \&2), 2431.

Fan, H, Guo, S, Jiao, Y, Zhang, R and Li, J (2007). Effects of exogenous nitric oxide on growth, active oxygen species metabolism, and photosynthetic characteristics in cucumber seedlings under $\mathrm{NaCl}$ stress. Front of Agriculture in China 1(3), 308-314.

Farooq, M, Aziz, T, Hussain, M, Rehman, H, Jabran, K and Khan, M B (2008). Glycinebetaine improves chilling tolerance in hybrid maize. Journal of Agro and Crop Science 194 (2), 152160.

Feng, J, Wang, C, Chen, Q, Chen, H, Ren, B and Li, X (2013). S-nitrosylation of phosphotransfer proteins represses cytokinin signaling. Nature 4, 15291529. doi: $10.1038 /$ ncomms 2541 . 
Freschi, L (2013). Nitric oxide and phytohormone interactions: current status and perspectives. Front in Plant Science 4, 398. doi: 10.3389/ fpls.2013.00398.

Gabaldon, C, Gomez, Ros L V, Pedreno, M A, Ros Barcelo, A (2005). Nitric oxide production by the differentiating xylem of Zinnia elegans. New Phytologist 165, 121-130.

Garcia-Mata, C and Lamattina, L (2001). Nitric oxide induces stomatal closure and enhances the adaptive plant responses against drought stress. Plant Physiology 126, 1196-1204.

Garcia-Mata, C and Lamattina, L (2002). Nitric oxide and abscisic acid cross talk in guard cells. Plant Physiology 128, 790-792. doi: 10.1104/pp.011020.

Kong, J, Dong, Y, Xu, L, Liu, S and Bai, X (2014). Effects of foliar application of salicylic acid and nitric oxide in alleviating iron deficiency induced chlorosis of Arachis hypogaea L. Botanical Studies 55(9), 1-9.

Le Roux Y, and Pages, L (1994). Developpement et polymorphisme racinaires chez de jeunes semis d'hevea (Hevea brasiliensis). Canadian Journal of Botany 72, 924-932.

Lombardo, M C, Graziano, M, Polacco, J C and Lamattina, L (2006). Nitric oxide functions as a positive regulator of root hair development. Plant Signalling \& Behaviour 1, 28-33.

Malamy, J E and Benfey, P N (1997). Down and out in Arabidopsis: the formation of lateral roots. Trends in Plant Science 2, 390-396.

Malamy, J E and Ryan, K S (2001). Environmental regulation of lateral root initiation in Arabidopsis. Plant Physiology 127, 899-909.
Mur, L A J, Mandon, J, Persijn, S, Cristescu, S M, Moshkov, I E, Novikova, G V, Hall, M A, Harren, F J M, Hebelstrup, K H and Gupta, K J (2012). Nitric oxide in plants: an assessment of the current state of knowledge. AoB PLANTS 5. pls052; doi:10.1093/aobpla/pls052.

Otvos, K, Pasternak, T P, Miskolczi, P, Domoki, M, Dorjgotov, D, Szucs, A, Bottka, S, Dudits, D and Feher, A (2005). Nitric oxide is required for, and promotes auxin-mediated activation of, cell division and embryogenic cell formation but does not influence cell cycle progression in alfalfa cell cultures. The Plant J 43, 849-860.

Pagnussat, G C, Simontacchi, M, Puntarulo, S and Lamattina, L (2002). Nitric oxide is required for root organogenesis. Plant Physiology 129, 954-956.

Pagnussat, G C, Lanteri, M L and Lamattina, L (2003). Nitric oxide and cyclic GMP are messengers in the indole acetic acid- induced adventitious rooting process. Plant Physiology 132, 12411248. doi: 10.1104/pp.103.022228.

Pagnussat, G C, Lanteri, M L, Lombardo, M C and Lamattina, L (2004). Nitric oxide mediates the indole acetic acid induction activation of a mitogen-activated protein kinase cascade involved in adventitious root development. Plant Physiology 135, 279-286. doi: 10.1104/pp.103.038554.

Premakumari, D and Sobhana, P (1995). Developmental anatomy of germinating seed of Hevea. Indian Journal of Natural Rubber Research 8, 8-12.

Santner, A, Calderon-Villalobos, L I and Estelle, M (2009). Plant hormones are versatile chemical regulators of plant growth. Nature Chemical Biology 5, 301-307. doi:10.1038/ nchem- bio.165. 
Scherer, G F E and Holk, A (2000). NO donors mimic and NO inhibitors inhibit cytokinin action in betalaine accumulation in Amaranthus caudatus. Plant Growth Regulation 32, 345-350. doi: 10.1023/A:1010750111550.

Seneviratne, P (2001). Budgrafting techniques and types of planting material. In: Hand Book of Rubber. Vol. 1: Agronomy pp.68-85 (Eds. L.M.K. Tillekeratne and A. Nugawela). Rubber Research Institute of Sri Lanka, Agalawatta, Sri Lanka.

Shen, Q, Wang, Y T, Tian, H and Guo, F Q (2012). Nitric oxide mediates cytokinin functions in cell proliferation and meristem maintenance in Arabidopsis. Mol. Plant. 6, 214-225. doi: 10.1093/mp/sss 148doi: $10.1093 / \mathrm{mp} / \mathrm{sss}$ 148.

Tan, J, Zhao, H, Hong, J, Han, Y, Li, H and Zhao, W (2008). Effects of exogenous nitric oxide on photosynthesis, antioxidant capacity and proline accumulation in wheat seedlings subjected to osmotic stress. World Journal of Agricultural Sciences 4(3), 307-313.
Thaler, P and Pages, L (1996). Competition within the root system of rubber seedlings (Hevea brassiliensis) studied by root pruning and blockage. Journal of Experimental Botany 48, 1451-1459.

Tian, X and Lei, Y (2006). Nitric oxide treatment alleviates drought stress in wheat seedlings. Biologia Planta 50(4), 775-778.

Zhang, H and Forde, B G (1999). Dual pathways for regulation of root branching by nitrate. Proceedings National Academic Sciences USA. 96, 6529-6534.

Zhang, M, An, L, Feng, H, Chen, T, Chen, K, Liu, Y, Tang, H, Chang, J and Wang, $X$ (2003). The cascade mechanisms of nitric oxide as a second messenger of ultraviolet B in inhibiting mesocotyl elongations. Photochemistry and Photobiology 77, 219-225.

Address for correspondence: Dr N M C Nayanakantha, Principal Research Officer, Plant Science Dept., Rubber Research Institute of Sri Lanka, Dartonfield, Agalawatta, Sri Lanka.

e-mail: nayanakanthachamil7@gmail.com 